\title{
PENTINGNYA PENGETAHUAN PERAWAT TENTANG BUDAYA KESELAMATAN PASIEN DI RUMAH SAKIT
}

\author{
Maranti Syah \\ Email: marantisyah555@gmail.com
}

\begin{abstract}
ABSTRAK
Latar Belakang: Budaya keselamatan pasien adalah suatu hal yang penting karena membangun budaya keselamatan pasien ialah suatu cara untuk membangun program keselamatan pasien secara keseluruhan. Membangun budaya keselamatan pasien dirumah sakit merupakan kewajiban dan tanggung jawab seluruh tenaga kesehatan termasuk salah satunya ialah perawat, karena perawat berperan penting dan memiliki kontak terbanyak dengan pasien. Keselamatan pasien menjadi bagian penting dalam pelayanan keperawatan yang dapat meningkatkan budaya keselamatan sehingga mengurangi dampak terjadinya insiden terhadap pasien. Akibat yang terjadi akibat dari rumah sakit yang tidak menerapkan keselamatan pasien dapat terjadi penurunan mutu pelayanan rumah sakit sehingga tingkat akreditasi akan menjadi penurunan. Tujuan: untuk menciptakan tempat keja yang nyaman, aman, dan sehat sehingga dapat meminimalkan serendah mungkin resiko atau insiden. Metode: Metode yang digunakan ialah menggunakan literature review. Hasil: Perawat mampu menerapakan budaya keselamatan psien dengan baik dan benar untuk mengurangi terjadinya kecelakaan atau resiko bahaya yang dapat membahayakan pasien di rumah sakit.
\end{abstract}

\section{Kata Kunci: Pengetahuan Perawat, Keselamatan Pasien, Rumah Sakit.}

\section{LATAR BELAKANG}

Keselamatan pasien ialah prinsip dasar dalam pelayanan kesehatan. Menurut Depkes RI (2008) Keselamatan pasien (patient safety) rumah sakit merupakan suatu sistem dimana rumah sakit membuat asuhan pasien lebih aman. Sistem tersebut seperti: assessmen risiko, identifikasi dan pengelolaan hal yang berhubungan dengan risiko pasien, pelaporan dan analisis insiden, kemampuan belajar dari insiden dan tindaklanjutnya serta implementasi solusi untuk meminimalkan timbulnya risiko. Sistem tersebut diharapkan mampu mencegah terjadinya insiden yang disebabkan oleh kesalahan akibat melaksanakan suatu tindakan atau tidak melakukan tindakan yang seharusnya dilakukan. 
Keselamatan ialah prinsip dasar dalam pelayanan pasien dan komponen kritis dari manajemen mutu. Keselamatan pasien merupakan sebuah transformasi budaya, dimana budaya yang diharapkan ialah budaya keselamatan, budaya tidak menyalahkan, budaya lapor dan budaya belajar.

Rumah sakit merupakan sarana pelayanan kesehatan yang dibutuhkan ketika seseorang sakit dan membutuhkan bantuan dengan tujuan untuk menyelamatkan kondisi pasien. Oleh sebab itu rumah sakit dituntut agar mampu mengelola kegiatannya dengan mengutamakan pada tanggung jawab para professional di bidang kesehatan, khususnya bagi tenaga medis dan tenaga keperawatan dalam menjalankan tugas dan kewenangannya.

Keselamatan pasien di rumah sakit meliputi partisipasi dari semua petugas kesehatan, terutama perawat. Perawat merupakan salah satu tenaga kesehatan yang mempunyai jumlah cukup dominan di rumah sakit yaitu sebesar 50 sampai $60 \%$ dari jumlah tenaga kesehatan yang ada.

Penilaian mutu rumah sakit didapatkan dari sistem akreditasi, salah satunya ialah sasaran keselamatan pasien karena telah menjadi prioritas untuk layanan kesehatan di seluruh dunia (Join Commission
International, 2015; Cosway, Stevens, \& Panesar, 2012). Salah satu langkah memperbaiki mutu pelayanan ialah melalui penerapan budaya keselamatan pasien di rumah sakit baik pemerintah maupun swasta.

Perilaku perawat dalam melakukan pelayanan kesehatan dipengaruhi oleh berbagai macam faktor yang berkontribusi terhadap terjadinya insiden keselamatan pasien, salah satunya menurut Safety Attitudes Questionnaire (SAQ) Sexton et al (2006) ada 6 domain yang di nilai yaitu; Team work climate, safety climate, kepuasan kerja, stres, persepsi manajemen, dan lingkungan kerja.

Dalam Permenkes RI No. 1691/ MENKES/ PER/ VIII/ 2011 tentang Keselamatan Pasien Rumah Sakit, dikatakan Insiden keselamatan pasien yang selanjutnya disebut insiden ialah setiap kejadian yang tidak disengaja dan kondisi yang mengakibatkan atau berpotensi mengakibatkan cedera yang dapat dicegah pada pasien, terdiri dari Kejadian Tidak Diharapkan (KTD), Kejadian Nyaris Cedera (KNC), Kejadian Tidak Cedera (KTC) dan Kejadian Potensial Cedera (KPC).

Hampir semua tindakan medis menyimpan potensi resiko. Banyaknya jenis pemeriksaan dan prosedur, jenis obat, serta 
jumlah pasien dan staf rumah sakit yang cukup besar, merupakan hal potensial bagi terjadinya kesalahan medis (Medical Errors). Kesalahan yang terjadi dalam proses asuhan medis ini dapat mengakibatkan atau berpotensi mengakibatkan cedera pada pasien, bisa berupa Kejadian Tidak di harapakan (KTD) (Marseno, 2011).

Dalam upaya meminimalkan terjadinya (KTD) yang terkait dengan aspek keselamatan pasien, maka manajemen rumah sakit perlu menciptkan budaya keselamatan pasien yang merupakan pondasi utama dalam menuju keselamatan pasien. Budaya keselamatan pasien akan menurunkan (KTD) secara signifikan sehingga akuntabilitas RS dimata pasien dan masyarakat akan meningkat dan pada akhirnya kinerja RS pun meningkat menurut Sora dan Nieva (2004) dalam (Hamdani, 2007).

\section{METODE}

Metode yang digunakan merupakan literature review yang menggunakan analisis data dari berbagai sumber untuk menguraikan suatu masalah dan mengevaluasi masalah tersebut dan merangkum menjadi suatu pembahasan untuk menyelesaikan masalah tersebut. Literatur review merupakan uraian tentang teori, temuan, serta bahan penelitian lain yang didapatkan dari sebuah bahan acuan untuk dijadikan sebagai landasan kegiatan penelitian untuk menyusun kerangka pemikiran yang jelas dari perumusan masalah yang ingin di teliti.

Metode ini memberikan gambaran mengenai bagaimana penerapan budaya keselamatan pasien oleh perawat di rumah sakit. Metode ini memberikan penjelasan dan pembahasan dalam penerapan budaya keselamatan pasien oleh perawat yang dapat meningkatkan mutu kualitas pelayanan kesehatan di rumah sakit.

\section{HASIL}

Perawat mampu menerapakan budaya keselamatan pasien dengan baik dan benar untuk mengurangi terjadinya kecelakaan atau insiden bahaya yang dapat membahayakan pasien di rumah sakit. Pada literature review didapatkan hasil bahwa untuk meningkatkan kualitas kerja dan kepuasan pasien terhadap pelayanan kesehatan di rumah sakit, seorang perawat harus mampu memahami aspek-aspek dalam penerapan keselamatan pasien. Perawat wajib mengetahui tentang fungsi dan peran seorang perawat dan disarankan bekerja dengan memperhatikan fungsi dan perannya tersebut. Kesehatan dan keselamatan kerja sangat penting diterapkan oleh perawat karena jika terjadi 
sesuatu akan menimbulkan kerugian ekonomi yang tentunya tidak diinginkan.

Pentingnya kebijakan perawat dalam penerapan budaya keselamatan pasien yang nantinya dapat meningkatkan mutu pelayanan kesehatan. Reputasi perusahaan adalah modal pokok yang mencerminkan pada kemampuan perusahaan untuk memuaskan pelayanan kesehatan.

Budaya keselamatan pasien yang baik dapat meminimalkan terjadinya insiden yang berhubungan dengan keselamatan pasien. Perawat yang juga berperan sebagai champion keselamatan pasien telah diterapkan diberbagai rumah sakit di Indonesia. Penerapan budaya keselamatan pasien yang adekuat akan mendapatkan pelayanan keperawatan yang bermutu.

\section{PEMBAHASAN}

Keselamatan ialah prinsip dasar dalam pelayanan pasien dan komponen kritis dari manajemen mutu. Keselamatan pasien merupakan sebuah transformasi budaya, dimana budaya yang diharapkan ialah budaya keselamatan, budaya tidak menyalahkan, budaya lapor dan budaya belajar. Keselamatan Pasien (Patient Safety) adalah isu global dan komponen penting dari mutu layanan kesehatan, prinsip dasar dari pelayanan pasien dan komponen kritis dari manajemen mutu.
World Health Organization (WHO) mengatakan bahwa keselamatan pasien ialah masalah keseahatan masyarakat global yang serius. Pasien mengalami resiko infeksi $83,5 \%$ di Eropa dan bukti kesalahan medis menunjukkan sekitar 5072.3\%. Berdasarkan hasil pengumpulan data-data mengenai penelitian rumah sakit di berbagai negara, ditemukan Kejadian Tak Diharapkan (KTD) dengan rentang 3.2 - $16.6 \%$. Data keselamatan pasien (Patient Safety) tentang Kejadian Nyaris Cedera (KNC) dan Kejadian Tak Diharapkan (KTD) di Indonesia masih bisa dibilang jarang, namun di pihak lain terjadi peningkatan tuduhan malpraktik yang belum tentu sesuai dengan pembuktian akhir. Insiden pelanggaran terhadap patient safety sebesar 28,3\% yang dilakukan oleh perawat. Data kejadian pasien jatuh di Indonesia berdasarkan dari Kongres XII PERSI (2012) bahwa kejadian pasien jatuh tercatat sebesar 14\%, padahal untuk mewujudkan keselamatan pasien (patien safety) angka kejadian pasien jatuh seharusnya $0 \%$.

Salah satu tujuan dari keselamatan pasien yaitu menurunnya KTD yang merupakan bagian dari insiden keselamatan pasien. Untuk mencapai sebuah tujuan tersebut, maka disusunlah sasaran keselamatan pasien yang bertujuan untuk mendorong perbaikan spesifik dalam keselamatan 
pasien. Sasaran memperhatikan bagianbagian yang bermasalah dalam pelayanan kesehatan dan menjelaskan bukti serta solusi dari konsensus berbasis bukti dan keahlian atas permasalahan yang ada. Penyusunan sasaran ini terjurus kepada Nine Life-Saving Patient Safety Solutions dari WHO Patient Safety (2007) yang digunakan juga oleh Komite Keselamatan Pasien Rumah Sakit PERSI (KKPRS PERSI), dan dari Joint Commission International (JCI).

Teori Reason mengatakan bahwa insiden keselamatan pasien disebabkan oleh dua factor yaitu, kesalahan laten dan kesalahan aktif. Kesalahan laten terkait dengan insiden keselamatan pasien yang meliputi lingkungan eksternal, manajemen, lingkungan sosial atau organisasi, lingkungan fisik, interaksi antara manusia dan sistem. Budaya keselamatan merupakan bagian dari kesalahan laten yang terkait dengan manajemen, sedangkan indikator budaya keselamatan meliputi kerja sama, komunikasi, kepemimpinan, pelaporan dan respon terhadap kesalahan tidak menghukum. Kunci pencegahan cedera dalam pelayanan keperawatan ialah identifikasi risiko. Hal ini sangat tergantung dengan budaya kepercayaan, kejujuran, integritas, dan keterbukaan berkomunikasi dalam sistem asuhan keperawatan.
Budaya keselamatan pasien menurut Agency for Healthcare Research and Quality (AHRQ) dapat dinilai dari segi perspektif staf rumah sakit terdiri dari 12 dimensi diantaranya: kerja sama antar tim dalam unit, harapan dan tindakan oleh supervisor, pembelajaran tentang organisasi, dukungan dari manajemen untuk keselamatan pasien, persepsi secara keseluruhan, umpan balik terhadap error, komunikasi yang terbuka, frekuensi pelaporan kejadian, kerja tim antar unit, staf yang adekuat, penyerahan dan pemindahan dan respon yang tidak menyalahakan.

Budaya keselamatan pasien merupakan keyakinan, persepsi, perilaku dan kompetensi individu atau kelompok dalam suatu organisasi yang mempunyai komitmen untuk bersama-sama menciptakan lingkungan yang aman (Brady, et al,. 2012). Budaya keselamatan pasien sebagai produk dari individual, nilai-nilai kelompok, sikap, persepsi, kompetensi dan pola perilaku yang menentukan komitmen dalam manajemen keselamatan pasien (Ito, et al,. 2011).

Menciptakan budaya pelayanan kesehatan yang aman maka harus adanya tanggung jawab dari setiap petugas kesehatan untuk menanamkan nilai-nilai budaya keselamatan pasien disebuah rumah sakit. Nilai tersebut seperti kedisiplinan, 
kepatuhan terhadap standar prosedur, dan protokol yang ada, teamwork, adanya nilai kejujuran dan keterbukaan serta rasa saling menghormati. Membangun budaya keselamatan pasien adalah konsep yang menarik dan umumnya menjadi penting dan mendasar dalam mengatur operasional keselamatan pasien (Walshe \& Boeden, 2006).

Membangun budaya keselamatan pasien melibatkan seluruh staf di rumah sakit dapat meningkatkan keselamatan pasien didukung oleh peran kepala ruangan yang optimal. Upaya dari kepala ruangan dalam melaksanakan peran yang efektif diruangannya dapat mempengaruhi budaya keselamatan pasien.

Budaya keselamatan pasien yang baik dapat meminimalkan terjadinya insiden yang berhubungan dengan keselamatan pasien. Perawat yang juga berperan sebagai champion keselamatan pasien telah diterapkan diberbagai rumah sakit di Indonesia. Penerapan budaya keselamatan pasien yang adekuat akan mendapatkan pelayanan keperawatan yang bermutu. Pelayanan kesehatan yang bermutu tidak cukup dinilai dari segi kelengkapan teknologi, sarana prasarana yang canggih dan petuugas kesehatan yang profesional, namun juga dinilai dari proses dan hasil pelayanan yang diberikan (Ilyas, 2004). Budaya keselamatan pasien yang baik dapat meminimalkan terjadinya insiden yang berhubungan dengan keselamatan pasien.

Budaya keselamatan pasien ialah pilar gerakan keselamatan pasien di pelayanan kesehatan. Penerapan budaya keselamatan pasien akan dapat mendeteksi kesalahan yang akan dan setelah terjadi. Budaya keselamatan pasien tersebut dapat meningkatkan kesadaran untuk mencegah eror dan melaporkan jika ada kesalahan. Hal ini mampu memperbaiki outcome yang dihasilkan oleh rumah sakit tersebut. Rumah sakit harus mampu memiliki budaya aman agar setiap orang sadar dan memiliki tanggung jawab terhadap keselamatan pasien.

Budaya keselamatan pasien yang diharapkan di rumah sakit ialah budaya keselamatan positif yang ditandai dengan adanya alur informasi yang baik dan adanya proses komunikasi yang berkaitan dengan pembelajaran pada saat KTD, mempunyai pemimpin yang komit dan eksekutif yang bertanggung jawab serta pendekatan untuk tidak menyalahkan dan tidak memberikan hukuman pada insiden yang dilaporkan.

Budaya keselamatan pasien dapat diukur dengan standar pengukuran budaya keselamatan pasien yang dikembangkan beberapa organisasi. Beberapa oragnisasi 
yang mengembangkan standar pengukuran tersebut seperti, Agency of Healthcare Research and Quality (AHRQ), Manchester Patient Survey Assesment Framework (MaPSaF) yang mengatakan bahwa terdapat beberapa komponen dalam survei budaya keselamatan pasien. Meskipun adanya perbedaan jumlah elemen, namun instrumen digunakan untuk mengukur komponen yang ada pada budaya keselamatan pasien yaitu budaya keterbukaan (Informed Culture), keadilan (Just Culture), pembelajaran (Learning Culture), serta pelaporan (Reported Culture) (AHRQ, 2015).

Tidak ada lagi alasan untuk setiap rumah sakit untuk tidak menerapkan budaya keselamatan pasien karena bukan hanya kerugian secara materi yang didapat tetapi juga ancaman terhadap hilangnya nyawa pasien. Apabila masih ada rumah sakit yang mengabaikan terkait dengan keselamatan pasien sudah seharusnya diberi sanksi yang berat bagi rumah sakit maupun petugas pelayanan kesehatan.

Apabila terjadi kelalaian bahkan kesengajaan dari pihak rumah sakit yang mengakibatkan terancamnya keselamatan pasien maka sudah seharusnya diberi tidak hanya sanksi internal tetapi juga sudah masuk ke ranah pidana. Inilah yang sampai saat ini belum dapat berjalan sehingga masyarakat yang dirugikan karena lemahnya penegakan hukum yang pada akhirnya kasusnya menguap begitu saja.

Ada beberapa faktor yang menjadi penyebab mengapa budaya keselamatan pasien belum benar-benar diterapkan di berbagai rumah sakit. Pertama, minimnya tingkat kepedulian petugas kesehatan terhadap pasien, hal ini bisa dilihat masih ditemukannya kejadian diskriminasi yang dialami oleh pasien terutama dari masyarakat yang kurang mampu. Kedua, beban kerja petugas kesehatan yang masih sangat berat terutama perawat. Perawatlah yang harus bertanggung jawab terkait asuhan keperawatan kepada pasien. Sedangkan disisi lain masih ada rumah sakit yang memiliki keterbatasan jumlah perawat yang dapat menjadikan beban kerja mereka meningkat. Ini dapat berdampak pada mutu pelayanan yang tidak sama di setiap rumah sakit. Ketiga, orientasi pragmatisme para petugas kesehatan yang saat ini masih hanya melekat disebagian petugas kesehatan.

\section{PENUTUP}

Keselamatan pasien ialah prinsip dasar dalam pelayanan kesehatan. Menurut Depkes RI (2008) Keselamatan pasien (patient safety) rumah sakit merupakan suatu sistem dimana rumah sakit membuat asuhan pasien lebih aman. Sistem tersebut seperti: assessmen risiko, identifikasi dan 
pengelolaan hal yang berhubungan dengan risiko pasien, pelaporan dan analisis insiden, kemampuan belajar dari insiden dan tindaklanjutnya serta implementasi solusi untuk meminimalkan timbulnya risiko.

Budaya keselamatan pasien merupakan keyakinan, persepsi, perilaku dan kompetensi individu atau kelompok dalam suatu organisasi yang mempunyai komitmen untuk bersama-sama menciptakan lingkungan yang aman (Brady, et al,. 2012). Budaya keselamatan pasien yang baik dapat meminimalkan terjadinya insiden yang berhubungan dengan keselamatan pasien.

\section{REFRENSI}

Buhari, B. (2019). Budaya Keselamatan Pasien Rumah Sakit Pemerintah Dan Rumah Sakit Swasta Di Kota Jambi. Jurnal 'Aisyiyah Medika. $3(1): 1-18$.

Herawati, Y. T. (2012). Budaya Keselamatan Pasien Di Ruang Rawat Inap Rumah Sakit $\mathrm{X}$ Kabupaten Jember. Jurnal IKESMA. 11(1):52-60.

Heriyati. Dkk. (2019). Budaya Keselamatan Pasien Rumah Sakit Umum Daerah Majene. Window of
Health : Jurnal Kesehatan. 2(3): 194-205.

Iriviranty, A. (2015). Analisis Budaya Organisasi dan Budaya Keselamatan Pasien Sebagai Langkah Pengembangan Keselamatan Pasien di RSIA Budi Kemuliaan Tahun 2014. Jurnal Administrasi Rumah Sakit. 1(3):196-206.

Mudayana, A. A. (2014). Peran Aspek Etika Tenaga Medis Dalam Penerapan Budaya Keselamatan Pasien Di Rumah Sakit. Supplemen Majalah Kedokteran Andala. 37(1):70-74.

Najihah. (2018). Budaya Keselamatan Pasien Dan Insiden Keselamatan Pasien Di Rumah Sakit: Literature Review. Journal of Islamic Nursing. 3(1):1-8.

Nurlindawati. Jannah, N. (2018). Budaya Keselamatan Pasien Oleh Perawat Dalam Melaksanakan Pelayanan Di Ruang Rawat Inap. JIM FKEP. 3(4):196-204.

Simamora, R. H., \& Fathi, A. (2019). The Influence Of Training Handover Based SBAR Communication For Improving Patients Safety. Indian 
journal of public health research \& development, 10(9), 1280-1285.

Ultaria, T. D. Dkk. (2017). Gambaran Budaya Keselamatan Pasien Di Rs Roemani Muhamaddiyah Semarang. Jurnal Kesehatan Masyarakat (E-Journal). 5(1):118125.

Wulandari, M. R. Dkk. (2019). Peningkatan Budaya Keselamatan Pasien Melalui Peningkatan Motivasi Perawat dan Optimalisasi Peran Kepala Ruang. Jurnal Kepemimpinan dan Manajemen Keperawatan. 2(2):58-66.

Yarnita, Y. (2018). Analisis Hubungan Sikap Perawat Dengan Budaya Keselamatan Pasien Di Ruang Rawat Inap Rsud Arifin Achmad Provinsi Riau. Jurnal Photon. $8(2): 81-85$. 